\title{
Validation of the German Version of the Quality of Dying and Death Questionnaire for Health Professionals
}

American Journal of Hospice \& Palliative Medicine ${ }^{(}$ 2016, Vol. 33(8) 760-769

(C) The Author(s) 2015

Reprints and permission: sagepub.com/journalsPermissions.nav DOI: $10.1177 / 1049909$ II5606075 ajhpm.sagepub.com

(9SAGE

\author{
Maria Heckel', Sonja Bussmann², Stephanie Stiel', \\ Christoph Ostgathe, MD', and Martin Weber, MD ${ }^{2}$
}

\begin{abstract}
Purpose: To validate the Quality of Dying and Death (Q०DD) instrument for health professionals (QoDD-D-MA) and to test its feasibility in 2 German palliative care units (PCUs). Methods: The QoDD was translated from English to German and then retranslated following European Organisation for Research and Treatment of Cancer (EORTC) guidelines. Data were collected in 2 German PCUs to calculate aspects of validity and reliability. Results: Mean total score was 83.05 (range 49-100; $N=232$ ). The QoDD-D-MA showed satisfactory psychometric properties, Cronbach $\alpha=.830$; interrater reliability $r=.245(P<.01)$. The QoDD-D-MA was independent of patients' demographic and clinical aspects. Some challenges occurred when applying the instrument. Conclusions: Feasibility could be improved by adapting the QoDD-D-MA to create a self-assessment version and finding a solution for items that result in many missing data. Future research should validate the QoDD-D-MA in other care settings.
\end{abstract}

\section{Keywords}

validation, psychometric properties, reliability, validity, quality of dying and death, assessment tool, palliative care

\section{Introduction}

Over the last few decades, a growing awareness regarding the necessity of adequate and feasible quality and outcome tools in palliative and hospice care has emerged. Many working groups have aimed to define suitable criteria to indicate the quality of palliative care. $^{1-6}$

Comprehensive care is an integral part of palliative and hospice care for imminently dying patients and their next of kin. Up to $50 \%$ of patients die during inpatient palliative care, ${ }^{7-9}$ meaning quality of care has to be extended to cover quality of dying and death in terms of quality management. Therefore, quality management and outcome initiatives in palliative and hospice care should contain information on patients' experience of dying and death.

A recent systematic review resulted in an extensive list of available outcome assessment tools in palliative care, yet little attention has been paid to the development of assessment tools that consider the experiences of dying patients. ${ }^{10}$ There is an urgent need for methodologically sound and feasible assessment tools pertaining to this specific issue.

Moreover, majority considerable percentage of imminently dying patients is not able to give self-reported information on their experience. ${ }^{11}$ Nevertheless, although self-reported outcome measures are known to be the gold standard in evaluating subjective patient perspectives, family caregivers or professionals tend to estimate symptoms deviant from the patient. ${ }^{12,13}$
Instead, either health professionals or informal caregivers are the first choice when looking for dialogue partners. They are closest to patients in their last days of life and are likely be able to best estimate patients' experience of dying and death afterward.

To evaluate the quality of dying and death, the assessment should reflect multidimensional perspectives, just as palliative care itself is based on multiprofessional care. The first tool attempting to measure the quality of the dying experience is the Quality of Dying and Death (QoDD) questionnaire, which was developed and validated by the working group led by Curtis et $\mathrm{al}^{14}$ and Patrick et $\mathrm{al}^{15}$ However, a validated German version does not yet exist. It may serve as a quality indicator to provide indirect information on clinical practice and to compare palliative and hospice care institutions and services (palliative care

\footnotetext{
'Department of Palliative Medicine, Comprehensive Cancer Center CCC Erlangen-EMN, Universitätsklinikum Erlangen, Friedrich-Alexander-Universität (FAU) Erlangen-Nürnberg, Germany

2 Interdisciplinary Palliative Care Unit, III. Department of Medicine, University Medical Centre of the Johannes Gutenberg University of Mainz, Mainz, Germany
}

\section{Corresponding Author:}

Stephanie Stiel, Universitätsklinikum Erlangen, Krankenhausstraße 12, 91054 Erlangen, Erlangen, 91054, Germany.

Email: stephanie.stiel@uk-erlangen.de 
units [PCUs], hospices, palliative home care services, and others) in terms of benchmarking.

In 2011, a multiprofessional working group from 2 universitybased palliative care services in Germany started a project to translate the QoDD ${ }^{16}$ into the German language and to validate it for use in the German palliative care context in order to help clinicians and researchers improve care for dying patients.

Two versions of the QoDD, a version for informal caregivers (German: QoDD-Deutsch-Angehörige, QoDD-D-ANG) and a version for health professionals (reported here; German: QoDD-Deutsch-Mitarbeiter, QoDD-D-MA), were formally validated by the working group in one study period. Detailed results of QoDD-D-ANG ${ }^{17}$ are published elsewhere. ${ }^{18}$

\section{Study Aim}

The aims of this project are to translate the QoDD for health professionals into German (QoDD-D-MA) and to formally validate it for use for health professionals caring for dying patients in PCUs. Here we report on the reliability and validity of the QoDD-D-MA, and its suitability and feasibility for standard implementation in German palliative care institutions.

\section{Methods}

\section{Study Population}

Health professionals who cared for patients who died during an inpatient stay in 2 PCUs (Mainz and Erlangen, Germany) between August 2012 and December 2013 (Mainz) and between September 2012 and August 2013 (Erlangen) were involved in the investigation.

\section{Patient Data Sets}

A standard data set with patients' personal data and data related to their care and disease collected as part of the German Hospice and Palliative Care Evaluation ${ }^{19}$ was used. As this is part of the routine documentation in both institutions, no additional patient data were collected explicitly for this validation study.

\section{Translation}

The translation process took place according to guidelines from EORTC, ${ }^{20}$ taking into account a sensitive adaptation to the palliative care setting and cultural adaptation. The translation procedure is comparable to that used for the version of the QoDD-D-ANG for informal caregivers. ${ }^{18}$ The original version of the QoDD was translated into German by 2 independent translators, and translations were discussed in an expert group. The gained final German translation was retranslated into English by 2 other independent translators without knowledge of the original version. Original version and retranslated versions were compared and discussed by the expert group, and the German translation was adapted where necessary. The translated items are shown in Table 1. Following experiences in clinical practice and in terms of the common practice of enhancing content validity, 2 items (amount of analgesics and artificial nutrition/liquids) were added, after discussion in the expert group, to adapt the instrument to the palliative care setting.

\section{Quality of Dying and Death Questionnaire for Health Professionals}

The QoDD-D-MA contains 23 items that contribute to a total score. These items represent different aspects of quality of dying and death such as control of symptoms, self-care, dignity, time spent with informal caregivers, spiritual needs, consultation with physicians about the end of life, medical care at the end of life, and the moment of death. The QODD-D-MA assesses a time period of the last 7 days of life. The responses for each item consist of 2 parts: (1) estimation of frequency ( $0=$ none to $5=$ always) or existence (yes or no) of a certain aspect for the patient and (2) rating of this aspect of the patient's dying experience $(0=$ terrible to $10=$ almost perfect).

The following 4 additional items ask for an overall rating of care in the last 7 days, and quality of the patients' dying, but are not included in the QoDD-D-MA total score:

- Do you think that your patient was kept alive too long?

- Overall, how would you rate the quality of your patient's dying?

- Rate the care your patient received in the last several days of his or her life while in the ICU from all doctors and other health care providers combined.

- Rate the care your patient received in the last several days of his or her life while in the ICU from his or her doctor.

The psychometric properties of these single items were not evaluated in detail here. For each item, the response options "not applicable" and "don't know" were provided.

The total score (resulting from the estimations from 0 to 10 given in the second part of the response to each of the 23 items) ranges from a minimum of 0 to a maximum of 100; higher scores are associated with better quality of dying and death. The mean score is calculated by adding together the estimated values of the items and dividing by the number of items answered. This mean score is divided by 10 and multiplied by 100 to calculate the total score. ${ }^{14}$

\section{Interviews}

Two questionnaires, the QoDD-D-MA and the German version of the Palliative Care Outcome Scale (POS), ${ }^{21}$ were filled in during a face-to-face interview attended by a trained researcher (Erlangen: MH, Mainz: SB). The interviews were planned to take place 7 days after the patient's death at the latest. At least 2 team members from different professional backgrounds who had been significantly involved in caring for the patient in the last days of his or her life were asked to consent to providing a joint estimation for items on the questionnaire. Therefore, they 
Table I. Items of Original Version (English) and Items of Translated Version (German).

Items of original version (English)

Appear to have his or her pain under control

Appear to have control over what was going on around him or her

Be able to feed himself or herself

Appear to breathe comfortably

Appear to feel at peace with dying

Appear to be unafraid of dying

Laugh, smile

Appear to keep his or her dignity and self-respect

Spend time with his or her family or friends

Spend time alone

Be touched or hugged by loved ones

Say goodbye to loved ones

Clear up bad feelings with others

Have one or more visits from a religious or spiritual advisor

Have a spiritual service or ceremony before his or her death

Did your patient receive mechanical ventilation during his or her stay?

Did your patient receive dialysis during his or her stay?

Do you think that your patient received the right amount of sedation during his or her stay?

Did your patient discuss his or her wishes for end-of-life care with his or her doctor-for example, resuscitation or intensive care?

Was anyone, including family, friends or staff, present at the moment of your patient's death?

In the moment before your patient's death, was he or she:Awake, asleep, or in a coma or unconscious

Additional items (not included in QoDD and QODD-MA total score)

Do you think that your patient was kept alive too long?

Overall, how would you rate the quality of your patient's dying?

Rate the care your patient received in the last several days of his or her life while in the ICU from all doctors and other health care providers combined.

Rate the care your patient received in the last several days of his or her life while in the ICU from his/her doctor.
Items of translated version (German)

Schmerzen schienen unter Kontrolle zu sein.

Schien Einfluss auf das zu haben, was um ihn herum geschah.

Konnte etwas zu sich nehmen.

Schien ruhig zu atmen.

Schien Frieden mit dem Sterben geschlossen zu haben.

Schien Angst vor dem Sterben zu haben.

Lachte, lächelte.

Schien seine Würde und Selbstachtung zu bewahren.

Verbrachte Zeit mit Familie oder Freunden.

Verbrachte Zeit alleine.

Wurde von Angehörigen berührt oder umarmt.

Verabschiedete sich von Angehörigen.

Klärte für sich ungute Gefühle, die anderen gegenüber bestanden.

Wurde ein- oder mehrmalig von einem Seelsorger/ spirituellem Begleiter besucht.

Ein Gottesdienst/ spirituelles Ritual fand vor seinem Tod statt.

Wurde Ihr Patient während der letzten sieben Tage auf der Palliativstation künstlich beatmet?

Wurde der Patient während der letzten sieben Tage auf der Palliativstation dialysiert?

Denken Sie, dass Ihr Patient während der letzten sieben Tage auf der Palliativstation die richtige Menge Sedativa erhalten hat?

Denken Sie, dass Ihr Patient während der letzten sieben Tage auf der Palliativstation die richtige Menge Analgetika erhalten hat? ${ }^{\mathrm{a}}$

Wurde der Patient während der letzten sieben Tage auf der Palliativstation künstlich ernährt (inkl. Flüssigkeit)? ${ }^{\mathrm{a}}$

Hat Ihr Patient seine Wünsche bezüglich der Betreuung am Lebensende während des Aufenthaltes auf der Palliativstation mit seinen Ärzten besprochen-z. B. Reanimation, Intensivmedizin, Palliative Sedierung?

War jemand (einschließlich Familie, Freunde oder Personal) zum Zeitpunkt des Todes Ihres Patienten anwesend?

War Ihr Patient unmittelbar vor dem Todeseintritt:Wach, somnolent (schlafend aber erweckbar) oder komatös (nicht erweckbar)

Denken Sie, dass Ihr Patient zu lange am Leben erhalten wurde? Insgesamt gesehen-wie würden Sie die Qualität des Sterbens Ihres Patienten einschätzen?

Schätzen Sie die Versorgung ein, die Ihr Patient in den letzten sieben Tagen seines Lebens auf der Palliativstation-von allen Ärzten und anderem betreuendem Personal zusammengenommen-erhalten hat.

Schätzen Sie die Versorgung ein, die Ihr Patient in den letzten sieben Tagen seines Lebens auf der Palliativstation von seinen Ärzten erhalten hat.

Abbreviations: QoDD, Quality of Dying and Death; QoDD-D-ANG, QoDD-Deutsch-Angehörige; QoDD-D-MA, QoDD-Deutsch-Mitarbeiter; ICU, intensive care unit.

${ }^{\text {a } I t e m s ~ a d d e d ~ i n ~ G e r m a n ~ v e r s i o n ~ f o r ~ p a l l i a t i v e ~ c a r e ~ c o n t e x t . ~}$

met the interviewer together and provided a consensus answer. The consensus answer was preferred to achieve higher denseness of information as one professional on its own could provide due to shifts and professional background. Additionally, during the pilot phase with a single interviewee, professionals remarked that they would feel more comfortable answering the items while reflecting together with colleagues to best represent multiple foci and perspectives on the patient deriving from different professions. The extent of interaction with patients before death is not quantifiable. As both PCUs provide primary nursing care and patients are mainly cared for by 1 physician and other professions are represented by 1 staff member each, the researchers were able to find the primary nurse and physician quite easily. In cases where the nurse or physician recommended another staff member who was present at the patient's bedside and death, the researchers contacted them. The interviews took 
place in the researcher's office or another undisturbed room at the PCU.

\section{Data Analyses}

The program IBM SPSS Statistics 21 (SPSS Inc, Chicago, Illinois) for Windows was used for statistical evaluation.

We performed descriptive statistics of patients' personal information and information related to their care and disease as well as information about health professionals in order to calculate means, frequencies, and standard deviations (SD) to describe the population investigated. We also used the frequencies of answers and percentage of missing values and skewness to gather information about the QoDD-D-MA items.

This study includes information on validity and reliability in accordance with the recommendations of Steiner and Norman ${ }^{22}$ regarding the main components of a health measurement instrument validation. Correlation coefficients higher than 0.1 were considered to indicate a fair effect, higher than 0.3 a moderate effect, and above 0.5 a substantial effect. ${ }^{23}$ Results were considered significant if $P<.05$. Content validity was carried out parallel to the validation of the QoDD-D-ANG for informal caregivers. $^{17}$

\section{Validity}

Construct validity. It was checked by means of factor analysis of the items of the QoDD-D-MA using a principal axis solution and direct oblimin rotation. Values of extracted factors greater than 1.0 were taken into account. A solution with factors representing the theoretical dimensions was expected.

Convergent validity. Correlations of the QoDD-D-MA with the results of the POS as an external criterion were checked for convergent validity using the hypothesis that another instrument measuring comparable aspects should show moderate to high correlation values. Higher sum scores in the POS indicate lower outcomes.

Discriminant validity (demographic and clinical factors). The palliative situation of the patients was described using the patient data sets. The association of different aspects related to disease and care with the QoDD-D-MA total score was examined with $t$ tests and Pearson correlations. This was to evaluate whether the QoDD-D-MA was sensitive to these factors. Although discriminant validity refers to showing no relationship between the global construct of interest and certain variables, the authors expected moderate correlations here as variables such as clinical and demographic factors are not entirely unrelated to the global construct of the QoDD-D-MA.

\section{Reliability}

Internal consistency. It was calculated by means of Cronbach $\alpha$ and Cronbach $\alpha$ if item deleted. Values between .7 and .9 were considered to indicate good internal consistency. ${ }^{24}$

Interrater reliability. Assessment of the QoDD-D-MA for health professionals was complemented by a second estimation by informal caregivers in the QoDD-D-ANG. ${ }^{17}$ Data were used to test for interrater reliability. The QoDD-D-ANG total scores were calculated in the same way as the QoDD-D-MA total scores. The results of the QoDD-D-ANG were as follows: in $18.6 \%$ of cases, more than $20 \%$ of items were missing. Total scores were not calculated for these 40 cases. The mean total score of 175 participants (informal caregivers) was 75.72, with scores ranging from 38 to 99 .

\section{Study Setting}

The project did not include any changes in the care or treatment of patients receiving palliative care. Only anonymized patient data collected as part of clinical routine were saved and processed electronically to describe the related patient group. For the investigation presented here, only data from health professionals were collected after patients' deaths.

This study was approved by the local ethics committees at both institutions (Erlangen Ethik-Kommission der Medizinischen Fakultät: 4427 04/13/2011 and Mainz Landesärztekammer Rheinland/Pfalz: 837.379.1 1 (7921) 10/24/2011).

All participating health professionals were informed about the study in general during a team meeting and gave written informed consent for all potential interviews for the period during which the study was conducted. They were informed that they could withdraw their consent at any time during the interview or the study period in general.

\section{Results}

\section{Recruitment}

A total of 296 patients were eligible for the assessment. One could not be assessed as it was not possible to organize an interview with the relevant staff members within an adequate time frame. Eventually, a total of 295 cases were enrolled in the study. In 31 (10.5\%) cases, only 1 health professional took part, 1 interview was completed by 3 professionals in consensus, and $89.5 \%$ were completed by 2 health professionals in consensus, in most cases a physician and a nurse (see Table 2).

\section{Study Population}

To describe the staff members, we used information about the occupational classification of the health professionals who participated (see Table 2) and information pertaining to the standard documentation concerning the deceased patients who had received palliative care.

The mean age of patients who received palliative care was 67.4 years ( $\mathrm{SD} \pm 14.4$, range 23.6-95.2 years), and 51.2\% were female. Patients stayed at the PCU for a median of 8 days. Their primary diagnoses are shown in Table 3.

\section{Length and Timing of Interviews}

The duration of the interviews ranged from 4 to 40 minutes and was 11.1 minutes on average $(n=259$; $\mathrm{SD} \pm 4.9)$. The duration of interviews could be assessed for $n=259$ cases for 
Table 2. Data Regarding Health Professionals and Interviews. ${ }^{\text {a }}$

\begin{tabular}{|c|c|c|}
\hline \multicolumn{3}{|l|}{$\begin{array}{l}\mathrm{N}=295 \text { cases } \\
\text { Personal data }\end{array}$} \\
\hline \multirow[t]{9}{*}{ Occupational groups } & Physician + nurse & 248 \\
\hline & Physician + spiritual advisor & 4 \\
\hline & Physician + psychologist & 5 \\
\hline & Nurse + psychologist & 4 \\
\hline & Nurse + spiritual advisor & 2 \\
\hline & Physician + psychologist + nurse & 1 \\
\hline & Psychologist & 2 \\
\hline & Physician & 20 \\
\hline & Nurse & 9 \\
\hline Interview duration $(\mathrm{N}=259)$ & & Mean II.I \pm 4.9 minutes, range $4-40$ minutes \\
\hline Time between death and interview $(\mathrm{N}=292)$ & & Mean 6.9 days \pm 6.4 days, median 6 days, range I-58 days \\
\hline \multirow[t]{2}{*}{ Gender } & Male & 13 \\
\hline & Female & 31 \\
\hline
\end{tabular}

${ }^{\mathrm{a}} \mathrm{N}=295$.

Table 3. Patient Demographic, Disease-Related, and Admission-Related Data. ${ }^{a}$

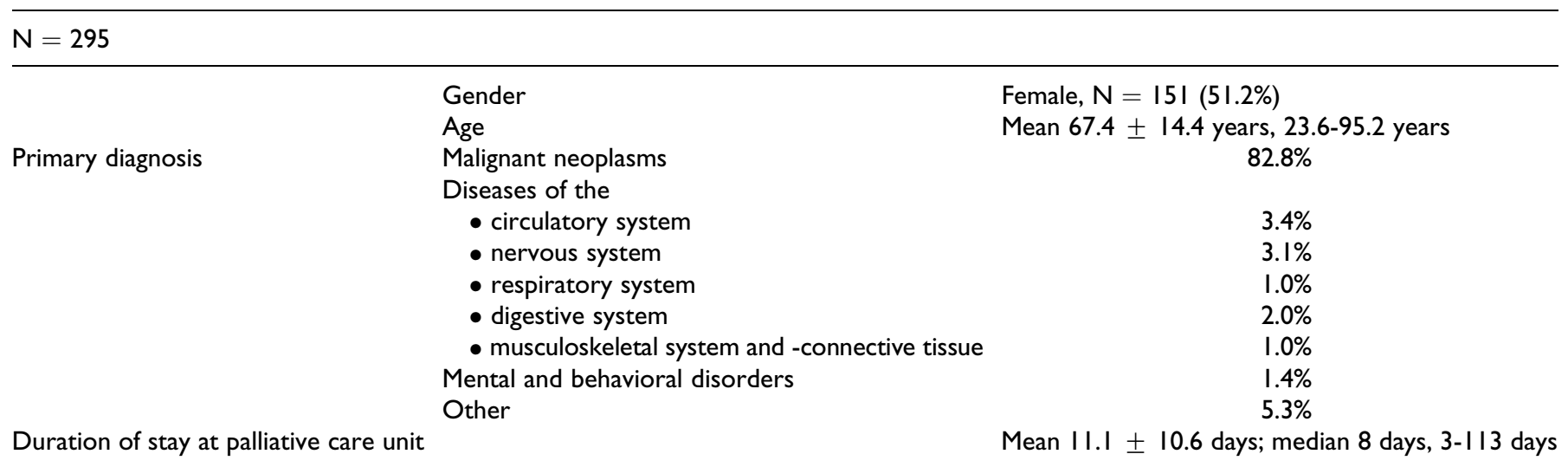

${ }^{\mathrm{a}} \mathrm{N}=295$.

whom the duration of the QoDD-D-MA excluding the duration of the questionnaire answering was registered.

The time that had to be invested in finding a suitable date for a meeting to do, the consensus estimation was not documented. This proved to be quite difficult due to different shifts and parttime workers. The result was a wide range of time spans (1- 58 days, median 6 days, $\mathrm{n}=292$, see Table 2) between the patient's death and the interview with health care professionals, which deviated from the study plan. For 7 interviews, the date of interview was not documented. The amount of interviews $(10.5 \%)$ conducted with a single health professional is also an indication of organizational difficulties.

\section{QoDD-D-MA Items and Total Scores}

Five items (clearing up bad feelings with others, saying goodbye to loved ones, mechanical ventilation, dialysis, and artificial nutrition/liquids) were dropped from the following analysis because more than $50 \%$ of respondents were not able to answer these questions (answered "don't know" or "not applicable"). The 18 items left were used for further analysis.
To calculate the total score, $20 \%$ of missing items were tolerated and imputed by the mean score for the missing items based on items completed by the interviewee/pair of interviewees. If more than $20 \%$ of items were missing, the total score was not calculated. Possible explanations for high amounts of missing values in these specific cases were reviewed.

In $21.3 \%$ of cases, more than $20 \%$ of items were missing. Total scores were not calculated for these 63 cases. The mean total score of 232 participants was 83.05 , and individual mean total scores ranged from 48.84 to 100 . For mean scores for single items, see Table 4.

There were significant group differences between the cases with more than $20 \%$ missing answers (group 1) and the cases with less than $20 \%$ missing answers (group 2). The distribution of the number of participating health care professionals differed between both groups. Each 2 health care professionals answered 50 cases from group 1 and 214 from group 2 versus each 1 health care professional answered 13 cases from group 1 and 18 cases from group $2(P<.01$ Fisher exact test $)$. The type of diagnosis (cancer/noncancer) showed differences as well: 38 and 207, respectively, for cancer; 25 and 25, respectively, for 
Table 4. Mean Scores for QoDD-D-MA Items Contributing to Total Score.

\begin{tabular}{|c|c|c|}
\hline QoDD-D-MA item & $\mathrm{n}$ & Mean score ${ }^{a}$ \\
\hline Pain under control & 293 & 8.34 (SD I.6) \\
\hline Control over what was going on around him or her & 281 & 7.83 (SD 2.3) \\
\hline Able to feed himself or herself & 275 & 6.67 (SD 2.7) \\
\hline Able to breathe comfortably & 294 & 7.53 (SD 2.6) \\
\hline Feel at peace with dying & 191 & 6.66 (SD 3.2) \\
\hline Be unafraid of dying & 176 & 7.27 (SD 3.0) \\
\hline Laugh and smile & 263 & 6.70 (SD 2.5) \\
\hline Keep his or her dignity and self-respect & 252 & 8.01 (SD 2.5) \\
\hline Spend time with other family and friends & 290 & 8.67 (SD 2.1) \\
\hline Spend time alone & 282 & 8.15 (SD 2.3) \\
\hline Touched or hugged by her or his loved ones & 248 & 8.69 (SD 2.0) \\
\hline Have one or more visits from a religious or spiritual advisor & 197 & 8.88 (SD I.7) \\
\hline Have a spiritual service or ceremony before his or her death & 187 & 8.85 (SD 2.0) \\
\hline Discuss his or her wishes for end of life care with his or her doctor & 243 & 8.46 (SD 2.3 \\
\hline Received the right amount of analgesics & 289 & 9.33 (SD I.4) \\
\hline Received the right amount of sedation & 289 & 9.27 (SD I.6) \\
\hline Anyone present at the moment of death & 238 & $8.90($ SD 2.1) \\
\hline In the moment before death, was he or she awake, asleep, in a coma/unconscious & 255 & 9.29 (SDI.3) \\
\hline
\end{tabular}

Abbreviations: QoDD-D-MA, QoDD-Deutsch-Mitarbeiter; SD, standard deviation.

'Mean scores of interviewees' estimations of item between 0 (= terrible dying experience) and 10 (= almost perfect dying experience).

noncancer $(P<.01$, Fisher exact test). Neither group showed significant differences for the following factors: age or gender of the patient, the ECOG estimated by health professionals, and the status of the patient in the moment before death (awake, asleep, in a coma, or unconscious).

The 4 additional items that were not included in the total score were answered as follows: in most cases, (98.3\%) pairs of interviewees thought that the patient was not kept alive for too long. In one case, they thought that the patient was kept alive too long and in one case they did not know. The overall rating $(0=$ worst health care possible to $10=$ best health care possible) of care provided by the whole team was seen as "best healthcare possible" in $85.4 \%$ of cases, and the overall rating of care provided by physicians as "best healthcare possible" in $84.4 \%$ of cases. These estimations showed minimal variances and no estimations under 4 were given. The overall quality of dying had an average score of 8.01 (SD 1.75) in $n=292$ cases $(0=$ terrible to $10=$ almost perfect $)$.

When comparing the QoDD-D-MA total scores of both PCUs, no significant differences were found between Erlangen and Mainz (mean total score $82.4 / 83.7 ; t$ test $t_{227}=.949$, $P=.344)$.

\section{Psychometric Properties}

\section{Validity}

Construct validity. Construct validity was investigated with an explorative factor analysis from 295 data sets with the 18item version of the QoDD-D-MA showing a moderate Kaiser-Meyer-Olkin criterion of 0.742 . Five factors with eigenvalues greater than 1.0 were extracted, explaining $43.8 \%$ of the total variance of the data. The extracted solution indicates a structure referring to the dimensions "spiritual needs," "dignity and self-determination," "symptom control," "social environment," and "attitude towards dying" (see Figure 1: items, percentage of estimation on scale points, and dimensions $[\mathrm{D} 1=$ spiritual needs, $\mathrm{D} 2=$ dignity and self-determination, D3 = symptom control, D4 = social environment, and D5 = attitude toward dying]). The factor intercorrelations ranged from -0.377 to 0.326 . The correlation of each 5 factors with the QoDD-D-MA total score ranged from $.503 *$ to $.833 *$ (see Table 5).]

Convergent validity. Convergent validity was tested by comparing POS sum scores to QoDD-D-MA total scores.

In 75 cases (25.4\%), it was not possible to obtain an overall score for POS due to a high amount of missing data. The Pearson correlation coefficient shows a 2 -sided significant $(P<.01)$ moderate correlation effect $r=-.492$.

Significant $(P<.01)$ correlations between QoDD-D-MA total scores and scores for the single item "How would you rate the quality of the patient's dying?" $(r=.528)$ were found using the Pearson correlation coefficient.

Discriminant validity (demographic and clinical factors). The health professionals' estimation of the quality of dying and death is significantly sensitive to the patient's duration of stay $(r=.130 ; P=.048)$, but independent of the patient's age $(r=$ $.058 ; P=.378)$, gender $\left(t_{230}=1.215 ; P=.226\right)$, ECOG $\left(t_{210}=\right.$ $.535 ; P=.593)$, malignancy of disease $\left(\mathrm{t}_{230}=.155 ; P=.877\right)$, survival since diagnosis $(r=.042 ; P=.539$; see Table 6$)$, and documented symptoms at admission (data not shown in detail).

Reliability. For reliability Cronbach $\alpha$ and Cronbach $\alpha$ if an item was deleted were calculated for the 18 items that were not optional and not excluded. Cronbach alpha was $\alpha=.830$. Cronbach $\alpha$ if an item was deleted ranged, for each single item, from 


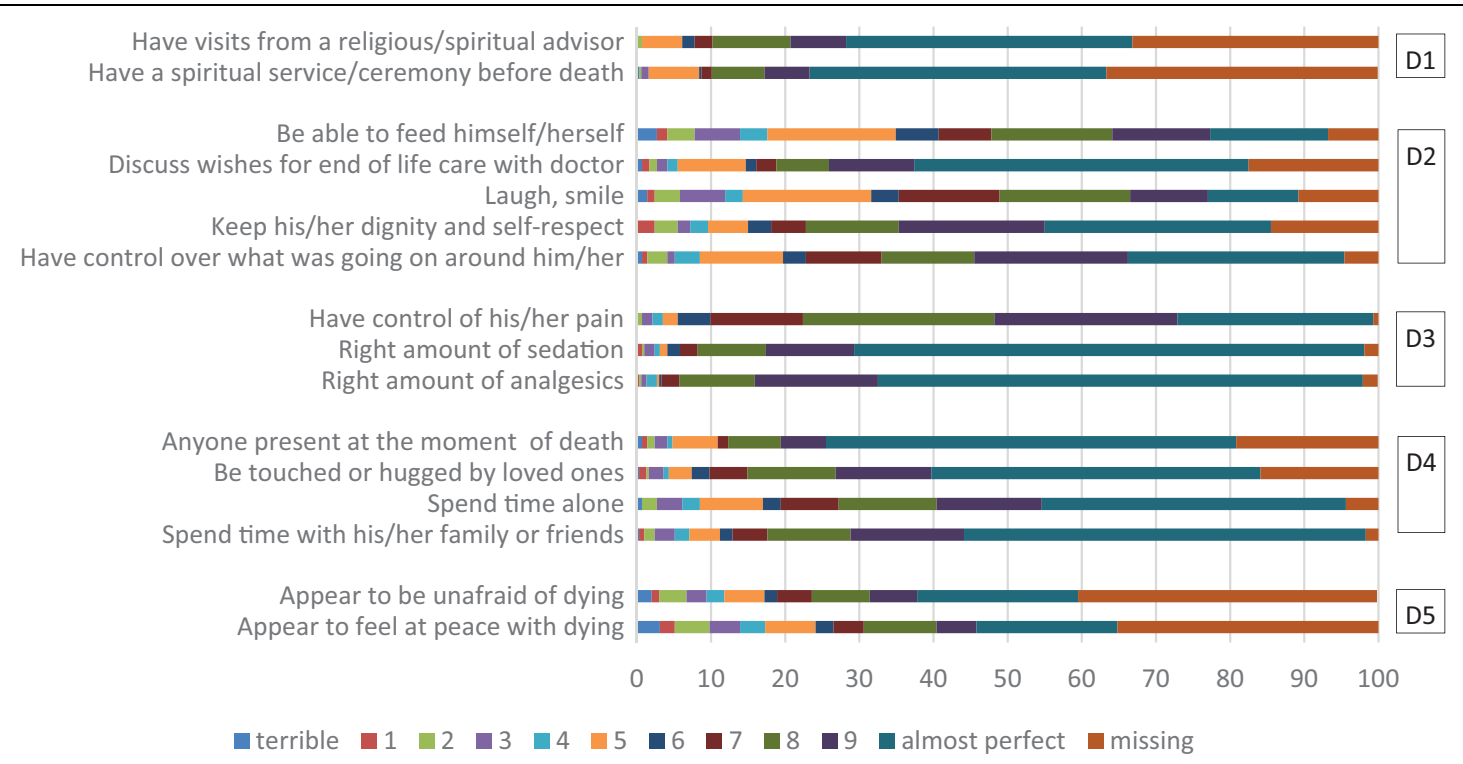

Figure I. Items, percentage of estimation on scale points, and dimensions (DI = spiritual needs, D2 = dignity and self-determination, D3 = symptom control, D4 = social environment, and D5 = attitude towards dying); I 6 items with eigenvalues greater than I.0 are included.

Table 5. Means, Standard Deviations, Minimum-Maximum (Range) and Correlation With QoDD-D-MA Total Score for 5 Extracted Factors From Factor Analysis.

\begin{tabular}{lcccrc}
\hline & N & Mean & SD & Minimum-maximum & Correlation with QoDD-D-MA total score \\
\hline Factor DI: spiritual needs & 166 & 17.72 & 3.3 & $4-20(0-20)$ & $.503^{\mathrm{a}}(\mathrm{n}=152)$ \\
Factor D2: dignity and self-determination & 205 & 39.04 & 7.4 & $12-50(0-50)$ & $.833^{\mathrm{a}}(\mathrm{n}=187)$ \\
Factor D3:symptom control & 285 & 27.01 & 3.4 & $5-30(0-30)$ & $.515^{\mathrm{a}}(\mathrm{n}=227)$ \\
Factor D4: social environment & 201 & 35.36 & 5.9 & $7-40(0-40)$ & $.617^{\mathrm{a}}(\mathrm{n}=180)$ \\
Factor D5: attitude toward dying & 159 & 14.48 & 5.7 & $0-20(0-20)$ & $.678^{\mathrm{a}}(\mathrm{n}=155)$ \\
\hline
\end{tabular}

Abbreviations: QoDD-D-MA, QoDD-Deutsch-Mitarbeiter; SD, standard deviation.

aLevel of significance: $P<.01$.

.813 to .837 . Deleting the item "able to breathe comfortably" (A4b) would improve the internal consistency to .837 .

Interrater reliability. To determine the correlation between the informal caregivers' and the health professionals' estimations, the total scores were calculated where possible. The Pearson correlation coefficient for matching cases $(\mathrm{n}=150)$ of the QoDD-D-ANG and the QoDD-D-MA was $r=.245$ and 2-sided significant $(P<.01)$.

\section{Discussion}

The quality of dying and death was rated positively by the participating health professionals. In comparison to other recent international studies, the mean total score reported here (QoDD-D-MA mean: 83.05; range: 48.84-100) is higher than for ICU nurses (mean ${ }^{25}$ QoDD 73.1, SD 21.425, (preintervention $^{26}$ : mean QoDD 78.3, SD 16.7; post intervention: mean QoDD 74.2, SD 21.726), (mean ${ }^{27} 66.9$, SD 16.327) and ICU physicians (mean 81.5, SD 17.327). ${ }^{27}$ The good results could, however, be seen as being influenced by social desirability due to the presence of research colleagues. To show whether the QoDD-D-MA could be used as a valid instrument in other settings, future studies should integrate different settings and places of death.

The interpretation of the results should consider that the QoDD-D-MA is not intended to directly measure quality of care but quality of the dying process estimated by health professionals. Nevertheless, team members may focus on quality of care. However, quality of care may substantially influence the estimated quality of dying. Additional items in which overall quality of care was rated were estimated as very positive and therefore showed little variance. This may indicate that the overall quality of care is consistently very good or may be a matter of wording $(0=$ "worst health care possible" to $10=$ "best health care possible"). These questions and the question as to whether the patient had been kept alive too long could be very interesting if compared with other settings offering endof-life care.

This validation study of the German version of the QoDDD-MA indicates that an assessment of the quality of dying of patients who have been cared for at a PCU is feasible with little 
Table 6. Patient Disease-Related, Care-Related, and Treatment-Related Information at Time of Admission to PCU and Association With QoDD-D-MA Total Score. ${ }^{a}$

\begin{tabular}{|c|c|c|c|c|c|}
\hline$N=232$ & & & Test & Test statistic & Significance \\
\hline Age of patient & & $\begin{array}{c}66.89 \pm 14.35 \text { years, } \\
\text { median }=69.66 \text { years } \\
\text { range } 24.8-93.0 \text { years }\end{array}$ & $\begin{array}{l}t \text { test }^{\mathrm{b}}, \text { Pearson } \\
\text { correlation }\end{array}$ & $\begin{aligned} t_{230} & =1.377 \\
r & =.058\end{aligned}$ & $\begin{array}{l}P=.170 \\
P=.378\end{array}$ \\
\hline Gender of patient & $\begin{array}{l}\text { Male } \\
\text { Female }\end{array}$ & $\begin{array}{l}37.3 \% \\
62.7 \%\end{array}$ & $t$ test & $t_{230}=1.215$ & $P=.226$ \\
\hline Duration of stay & & $\begin{array}{l}\text { Mean } 11.94 \pm 11.47 \text { days, } \\
\text { range } 3-113 \text { days }\end{array}$ & $\begin{array}{l}\text { Pearson correlation } \\
\text { coefficient }\end{array}$ & $r=.130$ & $P=.048$ \\
\hline $\begin{array}{l}\text { Patient stayed on PCU for last } \\
7 \text { days of life }(n=176)\end{array}$ & $\begin{array}{l}\text { Yes } \\
\text { No }\end{array}$ & $\begin{array}{l}63.1 \% \\
36.9 \%\end{array}$ & $t$ Test & $t_{174}=1.259$ & $P=.210$ \\
\hline $\operatorname{ECOG}(n=212)$ & $\begin{array}{l}0-2 \\
3-4\end{array}$ & $\begin{array}{l}10.8 \% \\
89.2 \%\end{array}$ & $t$ Test & $t_{(210)}=-.535$ & $P=.593$ \\
\hline $\begin{array}{l}\text { Cancer } \\
\text { Noncancer }\end{array}$ & & $\begin{array}{l}89.2 \% \\
10.8 \%\end{array}$ & $t$ Test & $t_{230}=.155$ & $P=.877$ \\
\hline Symptom complex sum & $\begin{array}{l}\text { None } \\
1 \\
2 \\
3 \\
4 \\
\text { Not known }\end{array}$ & $\begin{array}{l}16.3 \% \\
21.4 \% \\
32.2 \% \\
21.7 \% \\
7.1 \% \\
1.4 \%\end{array}$ & $\begin{array}{l}\text { Pearson correlation } \\
\text { coefficient }\end{array}$ & $r=.032$ & $P=.632$ \\
\hline Survival since diagnosis $(n=220)$ & & $\begin{array}{l}\text { Mean } 2.93 \pm 5.73 \text { years, } \\
\quad \text { range } 6 \text { days- } 68.44 \text { years }\end{array}$ & $\begin{array}{l}\text { Pearson correlation } \\
\text { coefficient }\end{array}$ & $r=.042$ & $P=.539$ \\
\hline
\end{tabular}

Abbreviations: QoDD-D-MA, QoDD-Deutsch-Mitarbeiter; PCU, palliative care unit.

${ }^{\mathrm{a}} \mathrm{N}=232$.

$\mathrm{b}_{t}$ Test for age-groups above and below median.

expenditure of time for health professionals. Nevertheless, the researchers had to organize meetings with at least 2 health professionals to conduct collaborative interviews, which was not always possible and used a high amount of staff resources. Some professionals told us that they personally liked the review of the patient's dying and death as a reflection on and an evaluation of their own efforts.

It appeared that there were a lot of missing data, despite the presence of a trained researcher to conduct the interview. This shows that for some items of the QODD-D-MA professionals did not feel able to answer. This may be because the patient was unconscious or because no opportunity to talk about the issue with the patient occurred (eg, clearing up bad feelings). Overall the study has shown satisfactory psychometric properties for the QoDD-D-MA. Construct validity showed some of the QoDD domains described. ${ }^{28}$ The 5 factors explain only $43.8 \%$ of total variance, which is considered not acceptable and needs further clarification of the constructs forming the questionnaire. Good internal consistency and results being independent of the patient's age, gender, ECOG, primary disease, survival time since diagnosis, and symptoms show the instrument as stable and mostly independent of demographic and care-related aspects. The QoDD-D-MA total score may be slightly sensitive to the duration of stay as staff members get to know patients better or patients may benefit from a longer stay and therefore have better quality of dying.

The lack of response, which even led to dropping some items from analysis, could indicate a problem with the items in the palliative care context (eg, mechanical ventilation and dialysis) or could represent neglected aspects of care (eg, death anxiety and spirituality, clearing up bad feelings with others, and saying goodbye to loved ones). These issues may be blind spots for physicians and nurses, given the larger number of missing values, as is clearly visible in the factor analysis in Figure 1, and could be an indication of aspects of patients' dying to which health professionals are not attentive enough.

The QoDD-D-ANG and QoDD-D-MA scores should correlate in some way, as they both measure the quality of dying of 1 patient. If they would correlate this could be an incidence that the instruments measure what they are meant to. Underlying assumption is that both informal caregivers and professionals have similar construct of quality of dying and death. ${ }^{15}$ The large proportion of missing data and the low correlation with caregiver assessment raise concerns about validity. Significant differences between family members' and attending physicians' ratings were also notable in a comparison of perceptions of the quality of dying and death by Levy et al. ${ }^{27}$

The instrument has some formal obstacles that may restrict its standard use in day-to-day clinical practice. The staff resources and time required to conduct the study and difficulties in analysis due to missing values show that some adaptations of the questionnaire are needed. The QoDD-D-MA should be adapted and validated as a self-assessment instrument for health professionals without guidance from a researcher if the team members are trained in advance.

The QoDD is the only international instrument and one of the few to measure quality of dying and death at all and, as the versions for different settings in the original language show, is 
adjustable. Therefore, we suggest validating a health professionals' self-assessment version in different settings and places where patients die to ensure that the QoDD-D-MA will spread as a standard documentation instrument. This could contribute to the development of a palliative care culture in all settings where patients die.

\section{Study Limitations}

The validation study is based on 2 inpatient PCUs. The results are not directly transferable to other settings. The health care professionals' answers could have been influenced by the fact that the researchers conducting the interviews were also working as team members with some of them. It is possible that health professionals' satisfaction with working conditions, treatment, and care influenced their answers. Occasionally the health professionals were not present all the time or were distracted by other tasks during the dying and death of the patients. Additionally, it is possible that one of the professionals was more dominant than the other in the consensus discussion, although researchers supervised the process. The consensus approach needs to be examined further and compared to a single responder approach. Until this examination took place, we recommend using consensus estimations where possible, despite the fact that our own experience shows difficulties in bringing 2 team members together who were both present at the patient's death (due to shifts, part-time jobs, or time available) within an appropriate timeframe.

The QoDD-D-MA gives no possibility to integrate patients' wishes for dying and death and therefore relies on the health professionals' estimation of quality of dying and death in place of the patient. To measure the individual quality of one person's dying and death, one would need to reconcile the patient's wishes and the relatives' rating of the dying experience after the patient's death. Otherwise, it is necessary to review to what degree the estimations of dying and death experiences made by health professionals are influenced by their own personal interpretations of and associations with a "good death," and their own expectations based on their care skills.

Recall bias might be a source of error as participants are not interviewed directly after the patients' death.

Test-retest reliability was rejected because of memory change, overlaps as several patients could die within a short period of time on a PCU, and additional loss of time for interviewees which did not justify repeated assessments.

Inter-rater reliability was examined based on the differences between health professionals and family caregivers. This was found to be rather moderate which is somewhat concerning as it is unclear which of the 2 external assessments (QODDD-MA or QODD-D-ANG) better represents the true patients' experiences.

\section{Conclusion}

The QoDD-D-MA showed satisfactory psychometric properties and some organizational challenges. In clinical routine, the
QoDD-D-MA could be integrated as a standard instrument if an adapted version could be developed with particular consideration of the problem of missing data for certain items and a self-assessment option and also proven to be valid. Future research should validate the instrument for other settings.

\section{Declaration of Conflicting Interests}

The authors declared no potential conflicts of interest with respect to the research, authorship, and/or publication of this article.

\section{Funding}

The authors received no financial support for the research, authorship, and/or publication of this article.

\section{References}

1. Claessen SJ, Francke AL, Belarbi HE, Pasman HR, van der Putten MJ, Deliens L. A new set of quality indicators for palliative care: process and results of the development trajectory. J Pain Symptom Manage. 2011;42(2):169-182.

2. De Roo ML, Leemans K, Claessen SJ, et al. Quality indicators for palliative care: update of a systematic review. J Pain Symptom Manage. 2013;46(4):556-572.

3. Aaronson NK, Ahmedzai S, Bergman B, et al. The European Organization for Research and Treatment of Cancer QLQ-C30: a quality-of-life instrument for use in international clinical trials in oncology. J Natl Cancer Inst. 1993;85(5):365-376.

4. Groenvold M, Petersen MA, Aaronson NK, et al. The development of the EORTC QLQ-C15-PAL: a shortened questionnaire for cancer patients in palliative care. Eur J Cancer. 2006;42(1): 55-64.

5. Hinz A, Singer S, Brahler E. European reference values for the quality of life questionnaire EORTC QLQ-C30: Results of a German investigation and a summarizing analysis of six European general population normative studies. Acta Oncol. 2014;53(7): 958-965.

6. Joyce CR, Hickey A, McGee HM, O'Boyle CA. A theory-based method for the evaluation of individual quality of life: the SEIQoL. Qual Life Res. 2003;12(3):275-280.

7. Radbruch L, Nauck F, Fuchs M, et al. What is palliative care in Germany? Results from a representative survey. J Pain Symptom Manage. 2002;23(6):471-483.

8. Radbruch L, Ostgathe C, Elsner F, et al. [What is the profile of palliative care in Germany. Results of a representative survey]. Schmerz. 2004;18(3):179-188.

9. CLARA Klinische Forschung and Clinical Analysis . Erfassung. HOPE-Download Berichte. 2013; Web site. https://www.hopeclara.de/download_1/. Accessed September 7, 2015.

10. Stiel S, Pastrana T, Balzer C, Elsner F, Ostgathe C, Radbruch L. Outcome assessment instruments in palliative and hospice care-a review of the literature. Support Care Cancer. 2012;20(11): 2879-2893.

11. Stiel S, Matthes ME, Bertram L, Ostgathe C, Elsner F, Radbruch L. [Validation of the new version of the minimal documentation system (MIDOS) for patients in palliative care: the German version of the edmonton symptom assessment scale (ESAS)]. Schmerz. 2010;24(6):596-604. 
12. Hodgkins M, Albert D, Daltroy L. Comparing patients' and their physicians' assessments of pain. Pain. 1985;23(3):273-277.

13. Grossman SA, Sheidler VR, Swedeen K, Mucenski J, Piantadosi S. Correlation of patient and caregiver ratings of cancer pain. J Pain Symptom Manag, 1991;6(2):53-57.

14. Curtis JR, Patrick DL, Engelberg RA, Norris K, Asp C, Byock I. A measure of the quality of dying and death. Initial validation using after-death interviews with family members. J Pain Symptom Manage. 2002;24(1):17-31.

15. Patrick DL, Curtis JR, Engelberg RA, Nielsen E, McCown E. Measuring and improving the quality of dying and death. Ann Intern Med. 2003;139(5 pt 2):410-415.

16. End-of-life care research program at University of Washington School of Medicine. Quality of Dying and Death (QoDD) Questionnaire for health professionals, Version 2.3. 2011 [cited 2011; Web site. http://depts.washington.edu/eolcare/ products/instruments/. Accessed September 7, 2015.

17. Heckel M, Busmmann S, Mai S, Stiel S, Weber M, Ostgathe C. Validierung des Fragebogens, Qualitiy of Dying and Death' (QoDD) für Nahestehende von Palliativpatienten im deutschen Sprachraum. Z Palliativmed. 2014;15(3):134.

18. Heckel M, Bussmann S, Stiel S, Weber M, Ostgathe C. Validation of the German Version of the Quality of Dying and Death Questionnaire for Informal Caregivers (QODD-D-Ang). J Pain Symptom Manag. 2015;50(3):402-413.

19. CLARA Klinische Forschung Clinical Analysis, Hospiz- und Palliativerfassung. Web site. https://www.hope-clara.de/download/ HOPE2009Basisbogen.pdf. 2009; HOPE Basisbogen. Accessed September 7, 2015.
20. Dewolf Linda, Kolle Michael, Velikova Galina, Johnson Collin, Scott Neil, Bottomley Andrew. EORTC Quality of Life Group Translation Procedure; 2009: Brussels, p. 32, ISSN 978-2-93006438-3.

21. Bausewein C, Fegg M, Radbruch L, et al. Validation and clinical application of the german version of the palliative care outcome scale. J Pain Symptom Manag. 2005;30(1):51-62.

22. Steiner DL, Norman GR. Health Measurement Scales: A Practical Guide to Their Development and Use. Oxford, UK: Oxford Univeristy Press; 1995.

23. Bortz J. Statistik für Human- und Sozialwissenschaftler. Berlin, Germany: Springer; 2005.

24. Terwee CB, Bot SD, de Boer MR, et al. Quality criteria were proposed for measurement properties of health status questionnaires. J Clin Epidemiol. 2007;60(1):34-42.

25. Hodde NM, Engelberg RA, Treece PD, Steinberg KP, Curtis JR. Factors associated with nurse assessment of the quality of dying and death in the intensive care unit. Crit Care Med. 2004;32(8): 1648-1653.

26. Treece PD, Engelberg RA, Crowley L, et al. Evaluation of a standardized order form for the withdrawal of life support in the intensive care unit. Crit Care Med. 2004;32(5): 1141-1148.

27. Levy CR, Ely EW, Payne K, Engelberg RA, Patrick DL, Curtis JR. Quality of dying and death in two medical ICUs: perceptions of family and clinicians. Chest. 2005;127(5):1775-1783.

28. Patrick DL, Engelberg RA, Curtis JR. Evaluating the quality of dying and death. J Pain Symptom Manage. 2001;22(3): 717-726. 